\title{
MEASUREMENTS PARAMETERS OPTIMISATION FOR X-RAY DIFFRACTOMETRY MEASUREMENTS OF STRESS STATE AROUND THE RIVETS
}

\author{
Elżbieta Gadalińska
}

\author{
Institute of Aviation, Warsaw, Poland
}

\begin{abstract}
$X$-ray diffractometry is one of the basic methods of stress measurement. This method was used to measure stress distributions around rivets as described further in this paper. There were two types of riveted samples, six types of samples made of rivet wire (after different types of treatment) and a aluminium sheet sample with three measurement areas: plate with both cladding and anodized layer, plate after removing the anodized layer and plate after removing both cladding and anodized layer. Riveted samples were prepared to measure the stress distribution around the rivets and the samples of wire and the plate with three areas were prepared to check the effect of different types of treatment on stress state.
\end{abstract}

\section{INTRODUCTION}

$\mathrm{X}$-ray diffractometry serves as a one of a number of methods for residual stress evaluation. The essential advantage of this method is that it is accurate and absolute. The diffraction of X-rays on a crystal lattice of a copper sulphate was detected by Max von Laue in 1912. The mathematical formula for this phenomenon was expressed by William Bragg and it is as follows:

$$
n \lambda=2 d \sin \theta
$$

where:

$n$ - is an integer determined by the order given,

$\lambda$ - is the wavelength of diffracting X-ray,

$d$ - is the spacing between the planes in the atomic lattice,

$\sin \theta$ - is the angle between the incident ray and the scattering planes.

The formula shows that the diffraction will occur only for unique Bragg's angles. Since its publication in 1913 the Bragg's law has been a powerful tool for studying crystals' structure. One of its applications is the residual stress measurement. The formula for stress calculation in a crystal is as follows:

$$
\sigma_{\varphi}=\left(\frac{E}{1+v}\right)_{h k l} \frac{1}{d_{0}}\left(\frac{\partial d_{\varphi \psi}}{\partial \sin ^{2} \psi}\right)
$$

All the stress measurement results presented here were obtained using a Stresstech Oy built Xray diffractometer model Xstress3000. It is a mobile device capable of performing measurements in two modes: $\psi$ and $\Omega$, with $\Phi$ rotation and $\Psi$ and $\Phi$ oscillation. There is a set of collimators from the $0,5 \mathrm{~mm}$ diameter to $5 \mathrm{~mm}$. This equipment is fully automated with a software controlled X-Y table for sequential measurements at a programmable set of points with given $\mathrm{X}-\mathrm{Y}$ coordinates. 
The purpose of this study was to determine the residual stress distribution around the rivets and compare it with the FEM analysis performed by R.P.G. Müller in his Ph.D thesis [1].

\section{SPECIMENS}

Four types of specimen were used:

1. Large specimens - metal sheets made of D16CzATV alloy, $2 \mathrm{~mm}$ thick; rivets made according to the standard OST 134040 - mushroom head rivets with the compensator.

2. Small specimens - made of D16AT alloy, $1.2 \mathrm{~mm}$ thick sheet; rivets made of W65 alloy, according to the Russian standard ANU 0301 - countersunk rivets with the compensator.

3. Specimens made of rivet wire (two types: $3,5 \mathrm{~mm}$ and $5 \mathrm{~mm}$ diameter) after different treatment:

- 1: polished with abrasive paper grade 100

- 2: polished with abrasive paper grade 100 , and then 280

- 3: polished as 2, and then grade 600

- 4: polished as 3, and then grade 1000

- 5: polished as 4 and polished with diamond paste, grain size $3 \mu \mathrm{m}$

- 6: polished as 5, and then polished electrolytically for $15 \mathrm{sec}$.

4. Specimen of a clad and anodized plate with three measurement areas: (1) original plate, (2) after removing the anodized layer with diamond paste, (3) after removing the anodized layer and cladding with abrasive paper grade from 280 to 800 and diamond paste, grain 3 $\mu \mathrm{m}$.

\section{FEM ANALYSIS RESULTS}

The first series of results obtained from FEM analysis by R.P.G Müller predicted the stress distribution on the mating surface, for rivets with a driven head on both sides (for radial and tangential stresses) and for countersunk rivets (for tangential stresses only).

The second series of results predicted the stress distribution through the thickness at the edge of the hole for rivets with a driven head on both sides (radial stresses only) and for countersunk rivets (radial and tangential stresses).

Measurements were performed at Stresstech Oy on the surface of the specimens so the comparison of the measurement results and the FEM analysis results is limited. For every specimen the appropriate value $D / D_{0}$ is 1,5 .

\section{RESULTS OF X-RAY DIFFRACTION MEASUREMENTS}

The X-ray measurements were performed on the surface of the specimen, on the side with the machined rivet head. The measurements were performed in radial $(\mathrm{phi}=0)$ and tangential directions $\left(\mathrm{phi}=90^{\circ}\right.$ ). The anodized layer and the cladding were not removed before measurement. 


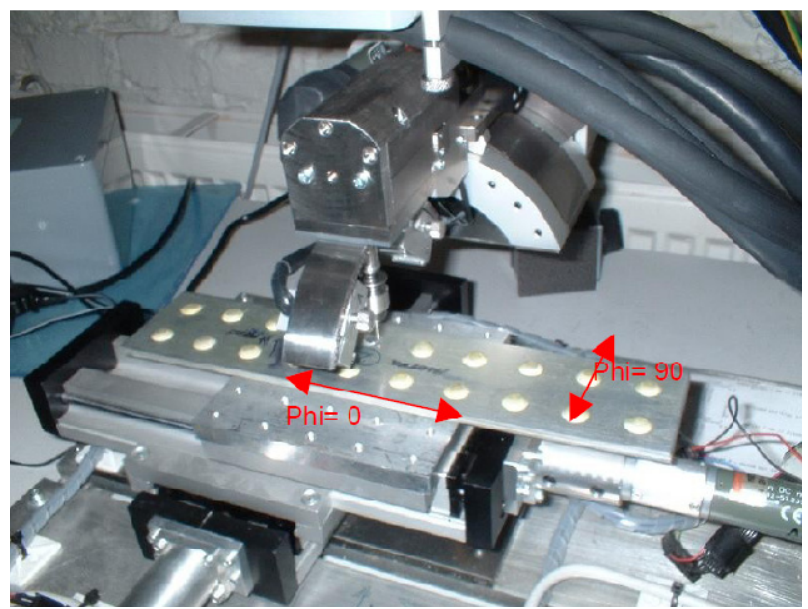

Phot. 1: Large specimen during the measurement. Directions of measured stresses.

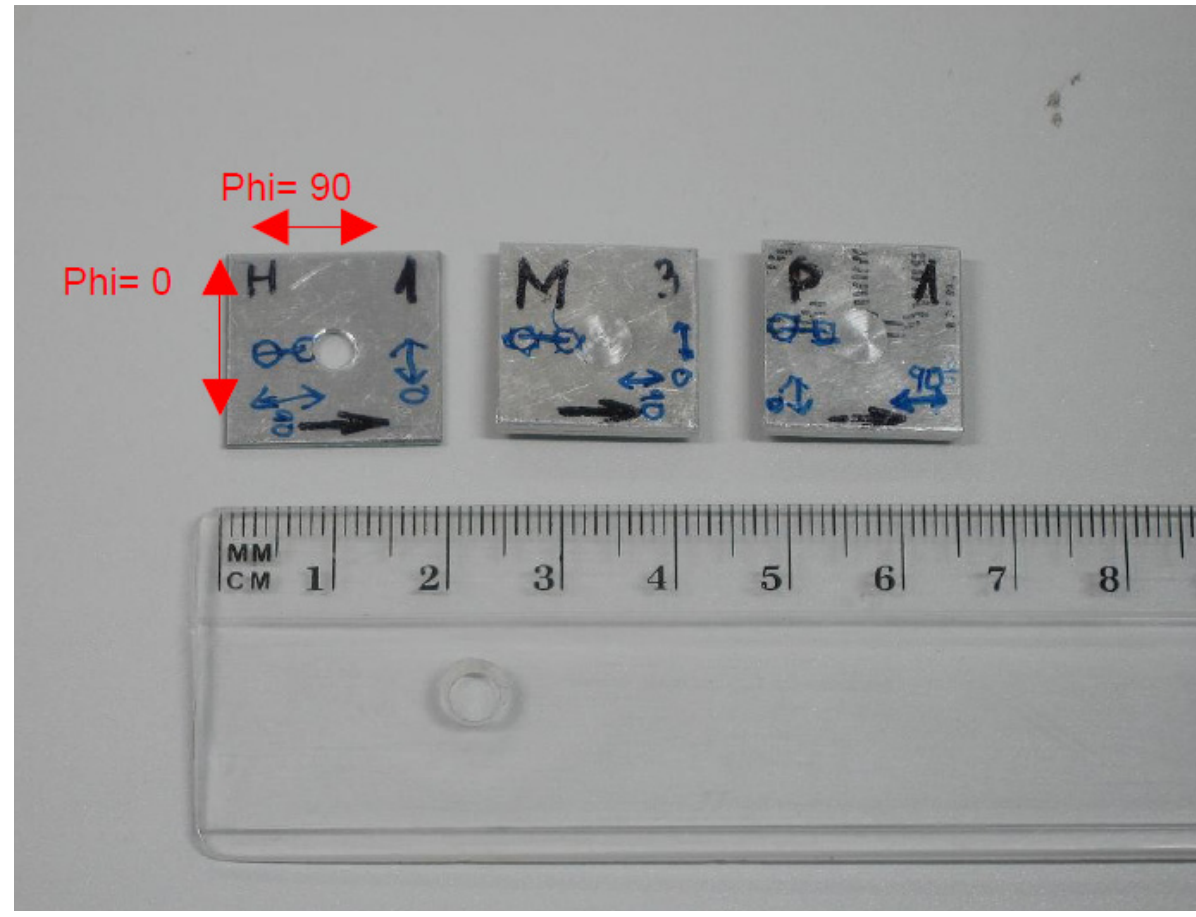

Photo 2: Small specimens. Directions of measured stresses.

The comparison of results obtained for presented specimens and the results obtained by R.P.G. Müller leads to the conclusion that the character of graphs obtained during the residual stresses measurement is inconsistent in each case.

The lack of consistency between the results of stress measurements and the FEM analysis forced the authors to analyze the measurement method and to improve it. It was stated that the reason for the error was the presence of the anodized layer and the cladding so it was necessary to work out the method of removing those layers to obtain more reliable results. The additional aim of preparing this type of specimen was to work out the method of removing the formed rivet head to enable the measurements under it. To check if the applied treatment hasn't changed the stress state, measurements were performed on the specimens made of wire for rivets, after different kinds of treatments. The results of stress measurements on those samples are listed below: 
Table 1. Results of the measurements on $3.5 \mathrm{~mm}$ diameter rivets, phi $=0^{\circ}$ corresponds to tangential direction and phi $=90^{\circ}$ to axial direction.

\begin{tabular}{|c|c|c|c|c|c|c|}
\hline Rivet & \multicolumn{2}{|c|}{$\begin{array}{c}\text { Stress phi=0 } \\
\text { Tangential } \\
\text { direction }\end{array}$} & \multicolumn{2}{|c|}{$\begin{array}{c}\text { Stress phi=90 } \\
\text { Axial direction }\end{array}$} & $\begin{array}{c}\text { FWHM } \\
\text { phi=0 }\end{array}$ & $\begin{array}{c}\text { FWHM } \\
\text { phi=90 }\end{array}$ \\
\hline no & MPa & \pm MPa & MPa & \pm MPa & $\circ$ & $\circ$ \\
\hline 1 & -63 & 4 & -50 & 5 & 1.43 & 1.46 \\
\hline 2 & -69 & 3 & -51 & 4 & 1.48 & 1.47 \\
\hline 3 & -28 & 3 & -41 & 3 & 1.49 & 1.48 \\
\hline 4 & -38 & 3 & -36 & 5 & 1.47 & 1.45 \\
\hline 5 & -39 & 5 & -44 & 2 & 1.43 & 1.43 \\
\hline 6 & -3 & 3 & -36 & 5 & 1.42 & 1.45 \\
\hline
\end{tabular}


Table 2. Results of the measurements on 5 mm diameter rivets, phi $=0^{\circ}$ corresponds to tangential direction and $p h i=90^{\circ}$ to axial direction.

\begin{tabular}{|c|c|c|c|c|c|c|}
\hline Rivet & \multicolumn{2}{|c|}{$\begin{array}{c}\text { Stress phi }=0^{\circ} \\
\text { Tangential } \\
\text { direction }\end{array}$} & \multicolumn{2}{|c|}{$\begin{array}{c}\text { Stress phi=90 } \\
\text { Axial direction }\end{array}$} & $\begin{array}{c}\text { FWHM } \\
\text { phi=0 }\end{array}$ & $\begin{array}{c}\text { FWHM } \\
\text { phi=90 }\end{array}$ \\
\hline no & MPa & \pm MPa & MPa & \pm MPa & $\circ$ & $\circ$ \\
\hline 1 & -56 & 4 & -49 & 6 & 1.44 & 1.45 \\
\hline 2 & -76 & 5 & -68 & 3 & 1.46 & 1.46 \\
\hline 3 & -68 & 2 & -61 & 5 & 1.47 & 1.47 \\
\hline 4 & -52 & 10 & -58 & 6 & 1.43 & 1.44 \\
\hline 5 & 15 & 3 & -15 & 5 & 1.47 & 1.45 \\
\hline 6 & -6 & 4 & -11 & 8 & 1.41 & 1.41 \\
\hline
\end{tabular}

The surface layers of the specimens were removed with 6 different types of treatment. The removed layers were thick enough and the treatment of step 5 and 6 gentle enough to uncover the core material of the wire without changing its stress state.

\section{SPECIMEN OF PLATE WITH THREE AREAS}

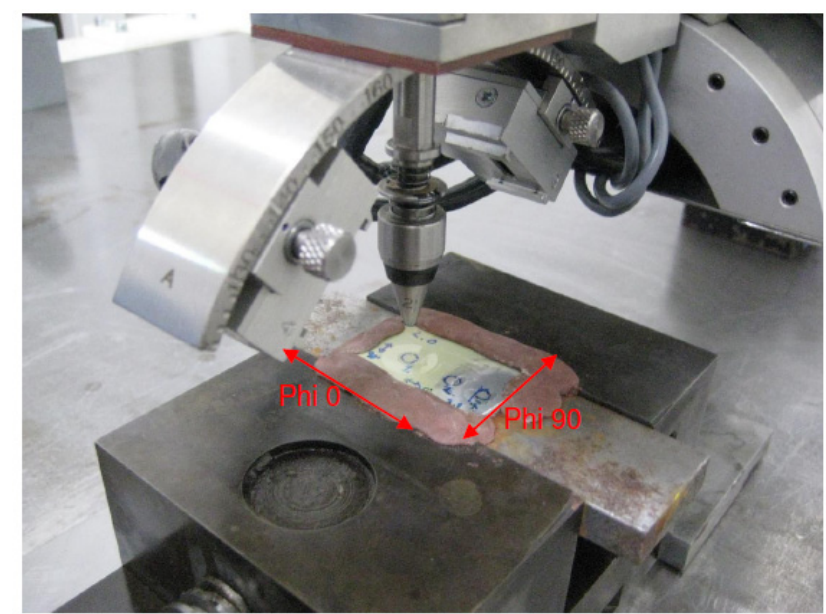

Photo 3. Plate with three different areas. Directions of measured stresses.

The measurements on those three areas were performed before the application of any additional treatment (depth $=0,000)$ and after removing a few microns of the surface layer by electropolishing. The aim of applying the additional treatment was to remove contamination of the specimen surface.

Table 3. Residual stress values on point 1.

\begin{tabular}{|c|c|c|c|c|c|c|}
\hline Plate & \multicolumn{2}{|c|}{ Stress phi $=0^{\circ}$} & \multicolumn{2}{l|}{${\text { Stress phi }=90^{\circ}}^{\circ}$} & $\begin{array}{c}\text { FWHM } \\
\text { phi }=0^{\circ}\end{array}$ & $\begin{array}{c}\text { FWHM } \\
\text { phi=90 }\end{array}$ \\
\hline Depth & MPa & $\pm \mathbf{M P a}$ & $\mathbf{M P a}$ & $\pm \mathbf{M P a}$ & ${ }^{\circ}$ & ${ }^{\circ}$ \\
\hline 0,000 & -24 & 7 & 6 & 10 & 1,30 & 1,31 \\
\hline 0,006 & -55 & 5 & -25 & 10 & 1,34 & 1,34 \\
\hline
\end{tabular}


Table 4. Residual stress values on point 2.

\begin{tabular}{|c|c|c|c|c|c|c|}
\hline Plate & \multicolumn{2}{|c|}{ Stress phi=0 } & \multicolumn{2}{c|}{ Stress phi=90 } & $\begin{array}{c}\text { FWHM } \\
\text { phi=0 }\end{array}$ & $\begin{array}{c}\text { FWHM } \\
\text { phi=90 }\end{array}$ \\
\hline Depth & MPa & \pm MPa & MPa & \pm MPa & $\circ$ & $\circ$ \\
\hline 0,000 & -35 & 5 & -68 & 5 & 1,31 & 1,32 \\
\hline 0,005 & -35 & 5 & -54 & 5 & 1,34 & 1,34 \\
\hline 0,008 & -53 & 7 & -61 & 8 & 1,34 & 1,35 \\
\hline
\end{tabular}

Table 5. Residual stress values on point 3.

\begin{tabular}{|c|c|c|c|c|c|c|}
\hline Plate & \multicolumn{2}{|c|}{ Stress phi $=\mathbf{0}^{\circ}$} & \multicolumn{2}{c|}{ Stress phi=90 } & $\begin{array}{c}\text { FWHM } \\
\text { phi=0 }\end{array}$ & $\begin{array}{c}\text { FWHM } \\
\text { phi=90 }\end{array}$ \\
\hline Depth & MPa & \pm MPa & MPa & \pm MPa & ${ }^{\circ}$ & ${ }^{\circ}$ \\
\hline 0,000 & -53 & 4 & -54 & 3 & 1,33 & 1,33 \\
\hline 0,005 & -45 & 3 & -60 & 5 & 1,31 & 1,31 \\
\hline
\end{tabular}

The difference between the results obtained for area no. 1 before applying the electropolishing and after removing 6 microns of the surface layer was caused by a different number of grains of aluminium participating in diffraction. The X-ray penetration depth is about 13 microns and the anodized layer thickness is about 7 microns. After removing 6 microns of the surface layer the measurement was performed almost only in the cladding layer.

\section{CONCLUSIONS}

The stress measurements around the rivets were not satisfactory enough. It was necessary to work out a method of removing the anodized layer and cladding to allow the stress measurements in the core material and compare them with the FEM analysis results.

\section{BIBLIOGRAPHY}

1. Muller, R. P. G. (1995). An Experimental and Analytical Investigation on the Fatigue Behavior of Fuselage Riveted Lap Joints. Ph. D. Thesis, pp.161. Netherlands: Delft University of Technology.

2. Hakanen, M. (2007). Institute of Aviation - XRD measurements on riveted samples, Unpublished report. Vaajakoski, Finland: Stresstech Oy. (\#699)

3. Hakanen, M. (2008). Institute of Aviation - Residual stress on rivets. Unpublished report. Vaajakoski, Finland: Stresstech Oy. (\#744)

4. Cullity, B. D. (1964). Fundamentals of X-ray diffraction. Warsaw: PWN.

5. ASM Handbook. (2004). Metallography and Microstructures. Vol. 9. ASM International.

6. ASM Handbook. (1990). Properties and selection: Nonferrous Alloys and Special-Purpose Materials. Vol. 2. ASM International.

7. Industrial standard of Soviet Union. Mushroom head rivets with compensator. (OST 134040 79)

8. Internal standard of PZL Mielec. Countersunk rivet. (ANU 0301) 